\title{
IMPROVED ACTIVITY DATA FOR ACCOUNTING GREENHOUSE GAS EMISSIONS DUE TO MANAGEMENT OF WETLANDS
}

\author{
Aldis Butlers, Jānis Ivanovs \\ Latvia State Forest Research Institute ‘Silava', Latvia \\ aldis.butlers@silava.lv
}

\begin{abstract}
The study represents results on remote sensing methods based evaluation of land use and land use changes in former and existing peat extraction areas in Latvia. The aim of the study is to elaborate activity data set for the National GHG inventory for the wetlands remaining wetlands for peat extraction. The study results provide sufficient data for application of the default emission factors for the peat extraction sites and flooded lands. Abandoned peat extraction fields, which are not yet afforested, flooded or rewetted should be reported as peat extraction sites following a conservative approach in application of the emission factors. The study results can be used to report land use changes since 1990; however, linearized approach in calculation of the land use change may result in overestimation or underestimation of GHG emissions in certain periods of time. According to study results, the area of peat extraction sites is considerably bigger than currently reported in the National GHG inventory, mainly due to considerable areas of abandoned peat extraction fields. Flooded lands may be a significant source of emissions and should be introduced in the National GHG inventory to secure consistency of reporting. Methodology for calculation of GHG emissions from flooded lands should be also elaborated. It is also necessary to elaborate emission factors for fertile and nonfertile peat extraction sites and continue work on separation of different soils in the inventory to increase accuracy of calculations.
\end{abstract}

Key words: greenhouse gas emissions, inventory, activity data, wetlands, peat extraction.

\section{Introduction}

Latvia is taking part in the worldwide climate change mitigation process and together with other countries Latvia signed the United Nations (UN) Framework Convention on Climate Change (UNFCCC) in the UN Conference on Environment and Development in 1992. The Parliament of the Republic of Latvia ratified the UNFCCC on February 23, 1995. On May 30, 2002 the Parliament ratified the Kyoto Protocol (KP). As a member of the European Union (EU), Latvia has obligations also under the Regulation No 525/2013 of the European Parliament and of the Council on a mechanism for monitoring and reporting GHG emissions and for reporting other information at national and the EU level relevant to climate change and repealing Decision No 280/2004/ EC. This regulation comprises reporting to fulfil the EU Effort Sharing Decision (406/2009/EC) and the EU LULUCF Decision (529/2013/EU). Commission Implementing Regulation No 749/2014 and the Commission Delegated Regulation No 666/2014 determine implementation of the Regulation No $525 / 2013$. Under the UNFCCC, KP and above mentioned regulations, Latvia is required to provide annual information on anthropogenic greenhouse gas (GHG) emissions by sources and removals by sinks of all GHG not controlled by Montreal Protocol from following sectors: Energy, Industrial Processes and Product Use, Agriculture, Land Use, Land Use Change and Forestry (LULUCF) and Waste.

During the second commitment period of the KP Latvia decided to account GHG emissions and removals from forest management as well as mandatory activities listed in the KP paragraph
3.3 - afforestation, reforestation and deforestation (Ministry of Environment and Regional Development of Republic of Latvia, 2015). According to the Proposal for a Regulation of the European Parliament and of the Council on the inclusion of greenhouse gas emissions and removals from land use, land use change and forestry into the 2030 climate and energy framework and amending Regulation No 525/2013 of the European Parliament and the Council on a mechanism for monitoring and reporting greenhouse gas emissions and other information relevant to climate change (LULUCF regulation) accounting of forest lands, grasslands and croplands will become mandatory in 2021 and accounting of wetlands will become mandatory in 2026, respectively these land use categories will have their emission reduction targets.

Managed organic soil is one of the largest key sources of GHG emissions in boreal and cool temperate moist climate regions in Europe (Salm et al., 2009). However, scientifically based accounting methods for GHG emissions have been developed and activity data are available mainly for organic soils in boreal climate region (Laiho, 2006; Lupikis et al., 2017; Lupiķis \& Lazdins, 2017; von Arnold et al., 2005). For instance, the default emission factors in the 2013 Supplement to the 2006 IPCC Guidelines for National Greenhouse Gas Inventories: Wetlands for forest land on drained nutrient-rich organic soils in the boreal zone are based on data from 62 sites, while for the temperate zone, there are data from only 8 sites and both nutrient-rich and poor soils are lumped together (Blain et al., 2013). Such a situation creates the risk of inconsistency of the GHG inventories and makes complicated planning 
of the mitigation measures in national and EU climate policies. Therefore, development of country-specific Tier 2 or Tier 3 GHG accounting methods including activity data sets and emission factors are urgently needed for a cool temperate moist climate region representing the majority of organic soils in the EU (Lupikis \& Lazdins, 2017).

GHG emissions from wetlands should also be evaluated in light of the climate change projections creating new challenges not only in forest management (Baders et al., 2017; Jansons et al., 2016), but also in development of climate sensitive mitigation strategies for managed organic soils. When the climate becomes warmer, GHG emissions will increase and current 'net sink' systems may turn into 'net emissions' systems (Norberg, 2017).

In Latvia, wetlands remaining wetlands is a key category of $\mathrm{CO} 2$ emissions. Latvia reports emissions (on-site and off-site) associated with industrial peat extraction in this category. Aggregated on-site emissions from soils in industrial peat-lands are equal for the whole time series due to lack of data about status of industrial peat-lands prepared for extraction 20 - 40 years ago. Off-site CO2 emissions are associated to the horticultural (non-energy) use of peat extracted and removed. Off-site emissions from peat used for energy are reported in the Energy Sector (Gancone et al., 2017; Lupikis et al., 2017). The net GHG emissions in wetlands in 2015 were $1012.05 \mathrm{kt}$ $\mathrm{CO} 2$ eq. $\mathrm{N} 2 \mathrm{O}$ and $\mathrm{CH} 4$ emissions contribute to about $0.2 \%$ and $1.4 \%$ of total emissions from organic soils (sum of on-site and off-site GHG emissions) in 2016 (Gancone et al., 2017).

According to the 2006 IPCC Guidelines, wetlands include the land that is covered or saturated by water for all or part of the year and that does not fall into the forest land, cropland, and grassland or settlement categories (Eggleston et al., 2006). In 2015, the total area of wetlands in Latvia was $445.18 \mathrm{kha}$, including $27.0 \mathrm{kha}$ of peat-lands drained for peat extraction (according to Table 3a.3.3 of the IPCC GPG LULUCF 2003, ed. Penman, 2003). In spite of several attempts to improve reporting of land use in Latvia, peat-lands drained for peat extraction are still reported using outdated activity data and in light of the requirements of the LULUCF regulation there is an urgent need to improve activity data on reporting of managed wetlands.

The aim of the study is to provide improved activity data for accounting greenhouse gas emissions from managed wetlands, particularly, to evaluate the status of peat extraction sites to avoid double accounting of emissions from soil.

\section{Materials and Methods}

The project methodology is based on remote analysis of existing spatial data sources representing land use and peat extraction - Forest inventory database (updated in 2015) maintained by State Forest Service (SFS), Land-parcel identification system (LPIS, updated in 2016) maintained by Rural Support Service (RSS), the vectorised topographic map (1:10000, updated in 2016) maintained by the Latvian Geospatial Information Agency (LGIA), Map of peatlands digitalized within the scope of the European Regional Development Fund project and maintained by Latvian Environment, Geology and Meteorology Centre (LEGMC). Printed maps of peat extraction licence areas provided by LEGMC were digitalized, georeferenced and validated against public raster maps within the scope of the earlier studies. Additional information used in the study is Landsat satellite image series from 1990 and aerophotographs (provided by LGIA) from 2nd to 5th cycle (2003 - 2015), as well as Sentinel II satellite image series from 2016.

Spatial analysis of the initial data was done using QGIS, Grass GIS and SAGA software tools. Spatial information is stored in Shapefile format, as multipart polygons. The classification of land use and vegetation types in former and existing peat extraction sites within the scope of the study is organized as multi-step procedure. The first step is creation of spatial layer containing all peat extraction sites. To create this layer digitalized information on peat extraction licences is visually compared with aerophotographs and borders of actual peat extraction fields (area within contour ditches and area covered by drainage ditches) are selected within borders of licence areas, which where updated to actual borders of peat extraction fields where necessary. Then aerophotographs are used to draw addition parts of the polygons outside licence areas nearby the existing extraction fields. Then normalized difference vegetation index (NDVI) is calculated for Landsat image fragments intersecting with Map of peatlands and supervised classification method is used to identify areas with NDVI index characteristic for peat extraction fields (Bastiaanssen, 1995). Areas exceeding 10 ha size are inspected visually using the oldest available aerophotographs and peat extraction fields not identified before are selected. The expert judgement is used to add former peat extraction fields not yet identified in licence database and in Landsat images. A distance between drainage ditches, the area surrounded by contour ditches and shape of fields are used as the criteria to identify and to draw borders of peat extraction sites. Attributes of intersecting or nearest objects in the Map of peatlands (LEGMC) are allocated to the identified peat extraction sites.

After creation of the spatial layer of former and existing peat extraction sites (PES) it is treated in two ways - by calculation of NDVI using Grass GIS and Sentinel II satellite image series and separation of woodlands from other lands and by visual inspection 
(using aerophotographs, 4th and 5th cycle) of water regime to separate flooded, rewetted and other areas. Visual inspection is also used to separate areas extracted by milling and by digging method. The threshold NDVI value for separation of forest and nonforest lands is 0.45 . After separation of woodlands and non-forest land areas covered by trees less than 0.1 ha in size is moved to non-forest lands. The water regime categories separated during the visual inspection are active or recently abandoned peat extraction sites (no vegetation or surface water, signs of peat extraction like roadside piles, road network, ditches are easily identifiable, these sites are considered as drained), sites where peat extraction is terminated (no fresh signs of peat extraction, no continuous woody vegetation, uncertain water regime); peat quarries extracted using digging method (not flooded, uncertain water regime); flooded areas (no continuous water cover, high groundwater level, considered as rewetted sites); ponds (small water bodies, considered as flooded areas); large water bodies (continuous water cover, considered as flooded areas); other lands (usually forest, cropland or grazing land, considered as drained).

The next step of the analysis is intersection of PES with Forest inventory database, LPIS and topographic maps to identify areas with legal status forest land, cropland, grazing land and settlements. The remaining area where peat extraction is terminated, peat is extracted using digging method and other lands is intersected with the spatial layer separating woodlands and non-forest lands according to Sentinel II data analysis. Additionally, all areas are intersected with peat extraction licensing spatial layer to separate areas where peat extraction is permitted according to existing agreements.

The resulting 2 sets (within and outside existing peat extraction licence fields) of spatial layers are: (1) forest land, (2) farmlands (cropland, grassland and orchards), (3) settlements, $(4,5)$ flooded areas (accordingly, ponds and large water bodies), (6) rewetted areas, former peat quarries including (7) afforested land and (8) area with herbaceous and shrub vegetation, abandoned peat extraction sites including (9) afforested land and (10) area with herbaceous and shrub vegetation, and other land including (11) afforested land and (12) area with herbaceous and shrub vegetation and (13) peat extraction sites. After intersecting the spatial layer were merged together and topology errors were manually corrected using QGIS built in functions. The errors were identified using Topology Checker tool. After correction of topology areas of polygons were recalculated and used for analysis.

Areas in the spatial layer 2 are already reported under cropland or grassland in the National GHG inventory, area in the spatial layer 3 is already reported under settlements, areas in the spatial layers 1, 7, 9 and 11 are already reported under forest land category, areas in the spatial layers 4, 5, 6, 8, 10, 12 and 13 should be covered by the default value from the Table 3a.3.3 of the IPCC GPG LULUCF 2003 used to characterize the land used for peat extraction.

The GHG emissions from areas in spatial layers 4 and 5 should be calculated according to the methodology for flooded lands (Vol. 4, Chapter 7, 2006 IPCC Guidelines, Eggleston et al., 2006), in the spatial layer 6 - according to methodology for rewetted lands (Chapter 3, Wetlands Supplement, Hiraishi et al., 2013), in the spatial layers 8, 10, 12, 13 - according to methodology for drained organic soils (Chapter 2, Wetlands Supplement, Hiraishi et al., 2013). Considering conservative approach emission factors for nutrient-rich soils in temperate moist climate region should be applied in the areas in the spatial layers 8, 10, 12 and the emission factors for nutrient-poor soils - in the spatial layer 13. For all land use categories emission factors for organic soils should be used to conform to the conservative approach in reporting of GHG emissions.

In the land use change calculation, it is assumed that peat extraction in quarries is terminated before 1990. In forest lands with records in the Forest inventory database, the actual age of forests is used to determine the year of afforestation. For other land use categories, linear regression is used assuming that former peat extraction areas transformed into a forest land, cropland and grassland, the settlement or flooded land gradually reached current land use structure in 2016.

\section{Results and Discussion}

The total area of former and existing peat extraction sites identified in the study is $54.9 \mathrm{kha}$. The total number of separate polygons is 237 and they are representing 185 records in the Map of peatlands (LEGMC). The average size of polygon is $0.2 \mathrm{kha}$. The total area of forest land legally transferred into a forest (spatial layer 1) is $9.6 \mathrm{kha}$, including $2.3 \mathrm{kha}$ afforested after 1990. Area of cropland and grassland (spatial layer 2) in former peat extraction sites is 0.8 kha. Area of settlements including summer cottages, houses, streets etc. (spatial layer 3) is 1.9 kha. According to Sentinel II data analysis only $16 \%$ (8.2 kha) of the former and current peat extraction sites conforms the selected NDVI threshold value.

The area of active peat extraction sites with easily identifiable signs of management activities (spatial layer 13) is 12.1 kha. Flooded areas are 5.3 kha including 0.2 kha of ponds (spatial layer 4) and 5.1 kha of larger water bodies (spatial layer 5). The rewetted area (spatial layer 6) is only 15 ha, because 


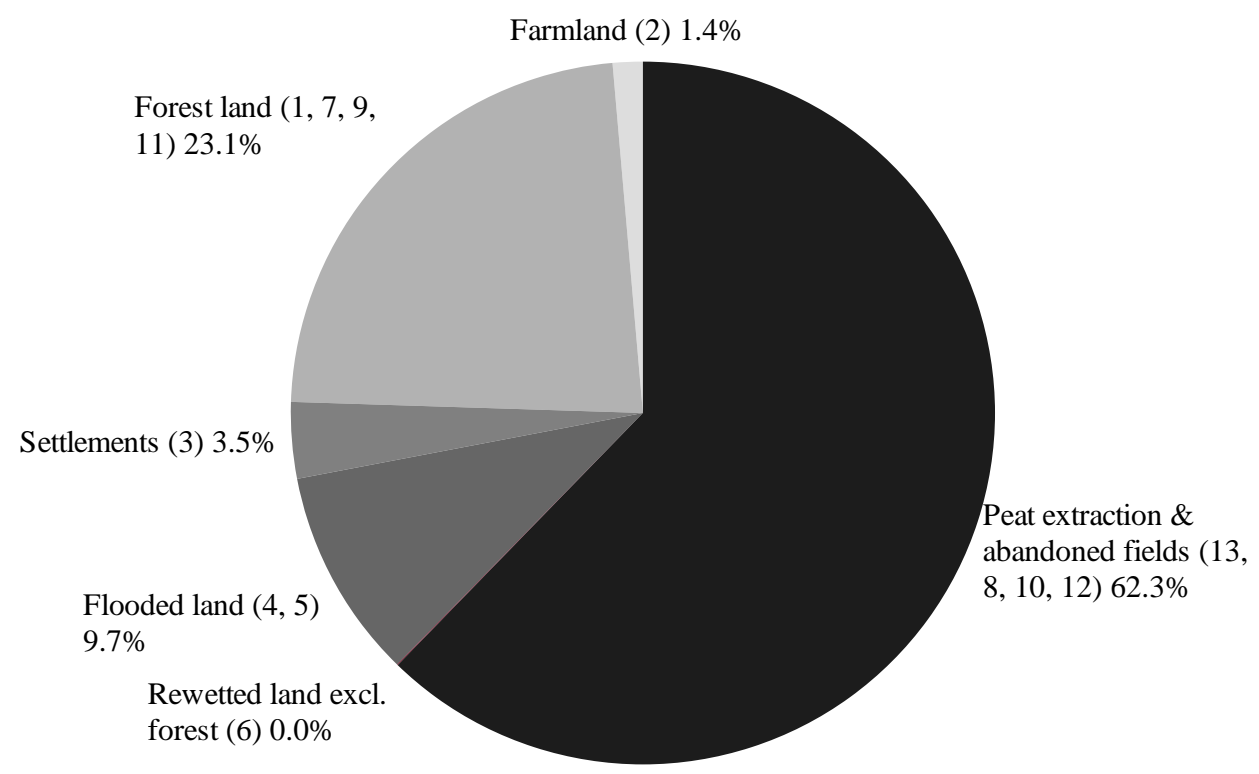

Figure 1. Distribution of area of extracted peatlands.

the areas under wet forests are already accounted as forest lands. The area of abandoned peatlands extracted using a digging method, excluding areas which are already transferred into Forest inventory database, is 114 ha. $16 \%$ of this area is already afforested (spatial layer 7) according to Sentinel II data analysis. The total area of identified peat quarries is $2.4 \mathrm{kha}$. The area of abandoned peatlands extracted using a milling method is $16.3 \mathrm{kha}$, including $0.3 \mathrm{kha}$ of afforested area (spatial layer 9) and 16 kha of areas covered mainly with herbaceous vegetation or small groups of trees (spatial layer 10). The area of other extracted peatlands is $8.7 \mathrm{kha}$, including $2.7 \mathrm{kha}$ of afforested area (spatial layer 11) and 6.0 kha of areas covered mainly with herbaceous vegetation or small groups of trees (spatial layer 12). Summary of the area distribution of extracted peatlands is shown in Figure 1. Most of the area is covered by currently active (spatial layer 13) and abandoned (not afforested yet) peat extraction sites (spatial layers 8, 10 and 12).

Most of peat quarries are already afforested. Active peat extraction continues in $22 \%$ of the total area of peat extraction areas. Flooded and rewetted land in total is $9.7 \%$ of the total from the area of land used for peat extraction. However, part of forests $(14 \%$ forests on wet mineral and organic soils, Figure 2) fulfils the main criteria for the rewetted land - a high groundwater level during the whole vegetation period.

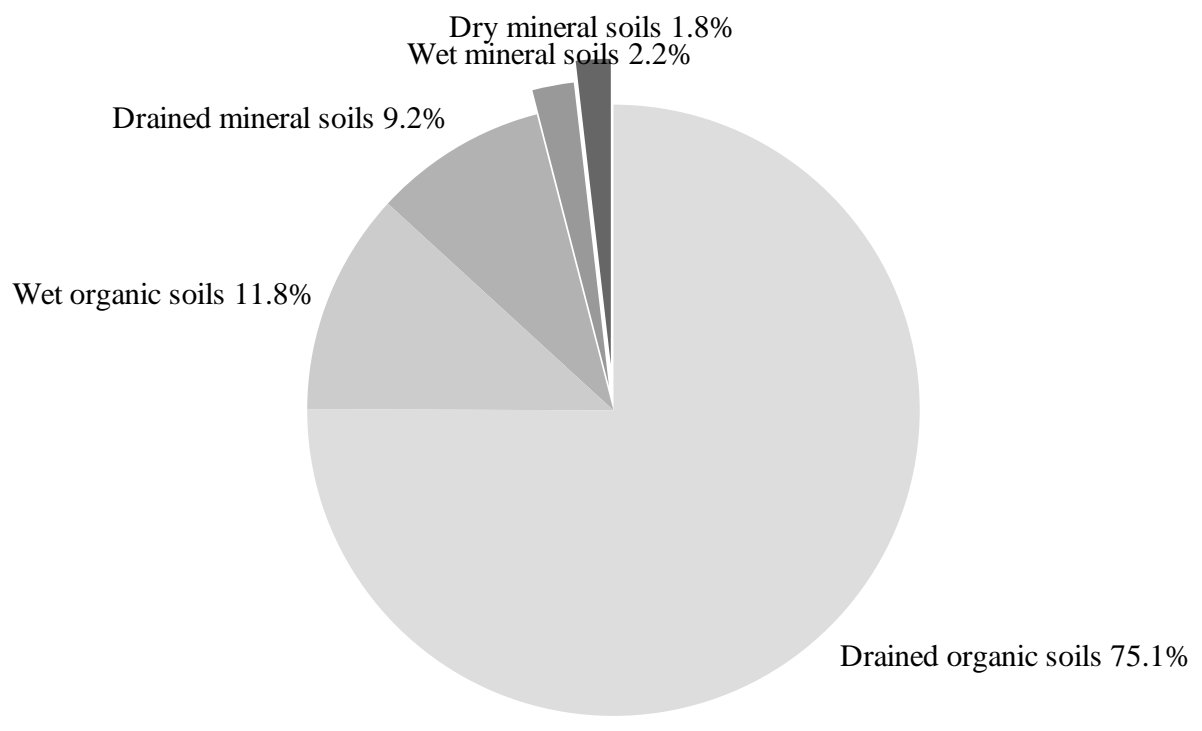

Figure 2. Distribution of area of extracted peatlands. 


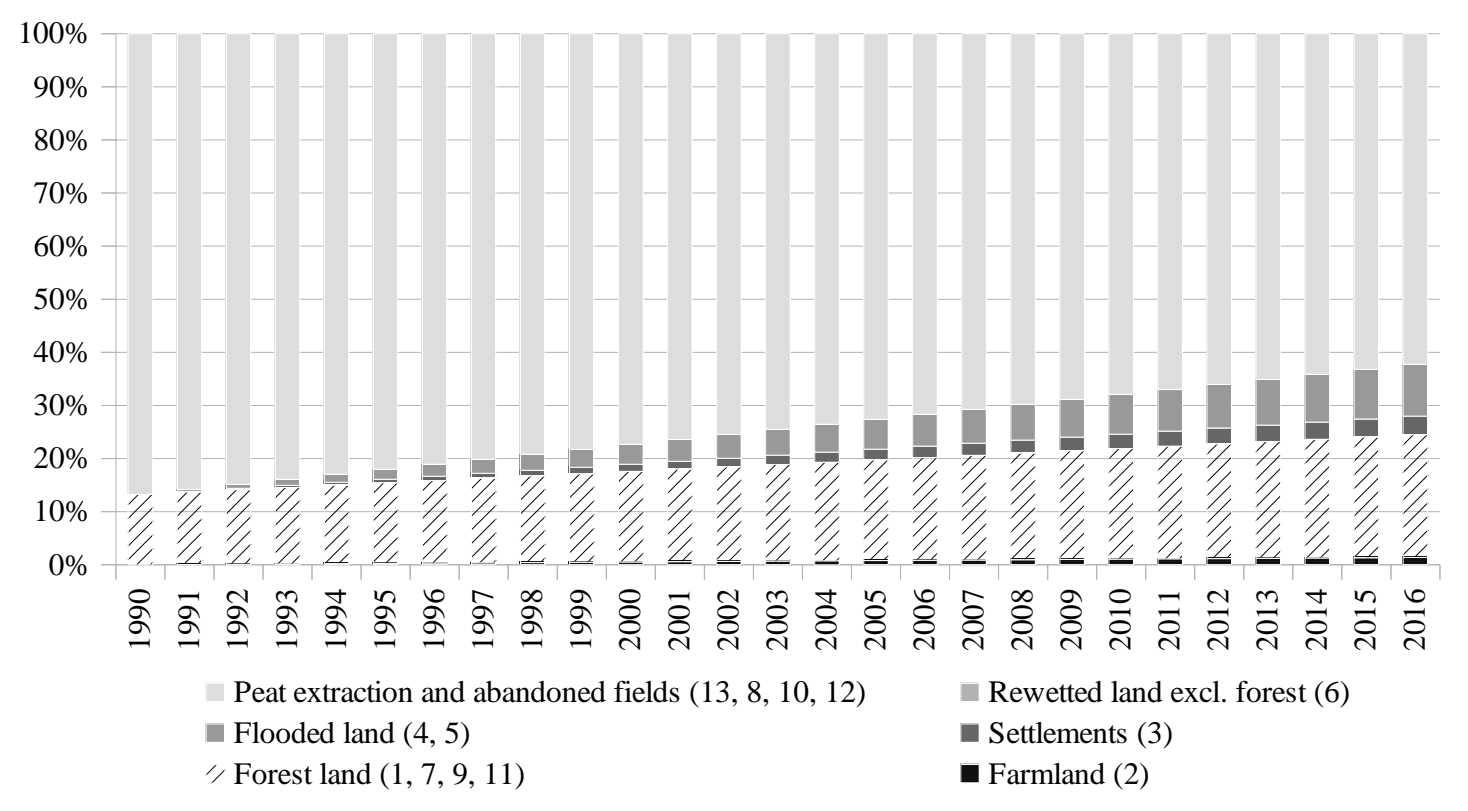

Figure 3. Linearized land use changes in areas used for peat extraction.

Forests on drained organic soils are $75.1 \%$ of the total forest area intersecting with the Forest inventory database, including 7\% (from the total forest area) of forests on fertile soils, where removals in litter and dead biomass do not compensate carbon losses from soil (Lupiķis \& Lazdins, 2017). Only 13.2\% of forests intersecting with the Forest inventory database are growing on mineral soils. Notably,drained and wet mineral soils may fulfil threshold values for organic soils according to IPCC 2006 (Eggleston et al., 2006).

Assuming that forests, which are older than 20 years and intersect with the Forest inventory database, changed their land use status before 1990, the total area of the former and existing peat extraction sites, which should be reported as wetlands in 1990 is $47.5 \mathrm{kha}$. The use of conservative approach in the calculation of GHG emissions requires an assumption that these lands were used or prepared for peat extraction in 1990, respectively, the most conservative emission factors (the ones for peat extraction sites and not for those used in wet organic soils) from the IPCC Wetlands supplement (Blain et al., 2013) should be applied to calculate GHG emissions to characterize GHG emissions in 1990. This assumption may lead to potential double accounting of GHG emissions in wetlands and forest land, because some of forests identified by the NDVI analysis in Sentinel II satellite images may be older than 20 years, but it fulfils requirements of conservative approach. Updated information on the age of forests not intersecting with the Forest inventory database would increase accuracy of the calculation of GHG emissions; however, gathering of such data, using accessible methodologies, is very costly and obtained emission reduction will not compensate the expenses.

Land use change estimates elaborated within the study are summarized in Figure 3 and Table 1. The area of peat extraction fields including abandoned

\section{Summary of land use changes}

Table 1

\begin{tabular}{|l|c|c|c|c|c|c|}
\hline \multicolumn{1}{|c|}{ Land use } & 1990 & 1995 & 2000 & 2005 & 2010 & 2016 \\
\hline Farmland (2) & 0.0 & 0.1 & 0.3 & 0.4 & 0.6 & 0.8 \\
\hline Forest land (1, 7, 9, 11) & 7.3 & 8.3 & 9.4 & 10.4 & 11.5 & 12.7 \\
\hline Settlements (3) & 0.0 & 0.4 & 0.7 & 1.1 & 1.5 & 1.9 \\
\hline Flooded land (4, 5) & 0.0 & 1.0 & 2.0 & 3.1 & 4.1 & 5.3 \\
\hline Rewetted land excl. forest (6) & 0.0 & 0.0 & 0.0 & 0.0 & 0.0 & 0.0 \\
\hline $\begin{array}{l}\text { Peat extraction and abandon fields } \\
(13,8,10,12)\end{array}$ & 47.6 & 45.1 & 42.5 & 39.9 & 37.3 & 34.2 \\
\hline Total area & 54.9 & 54.9 & 54.9 & 54.9 & 54.9 & 54.9 \\
\hline
\end{tabular}




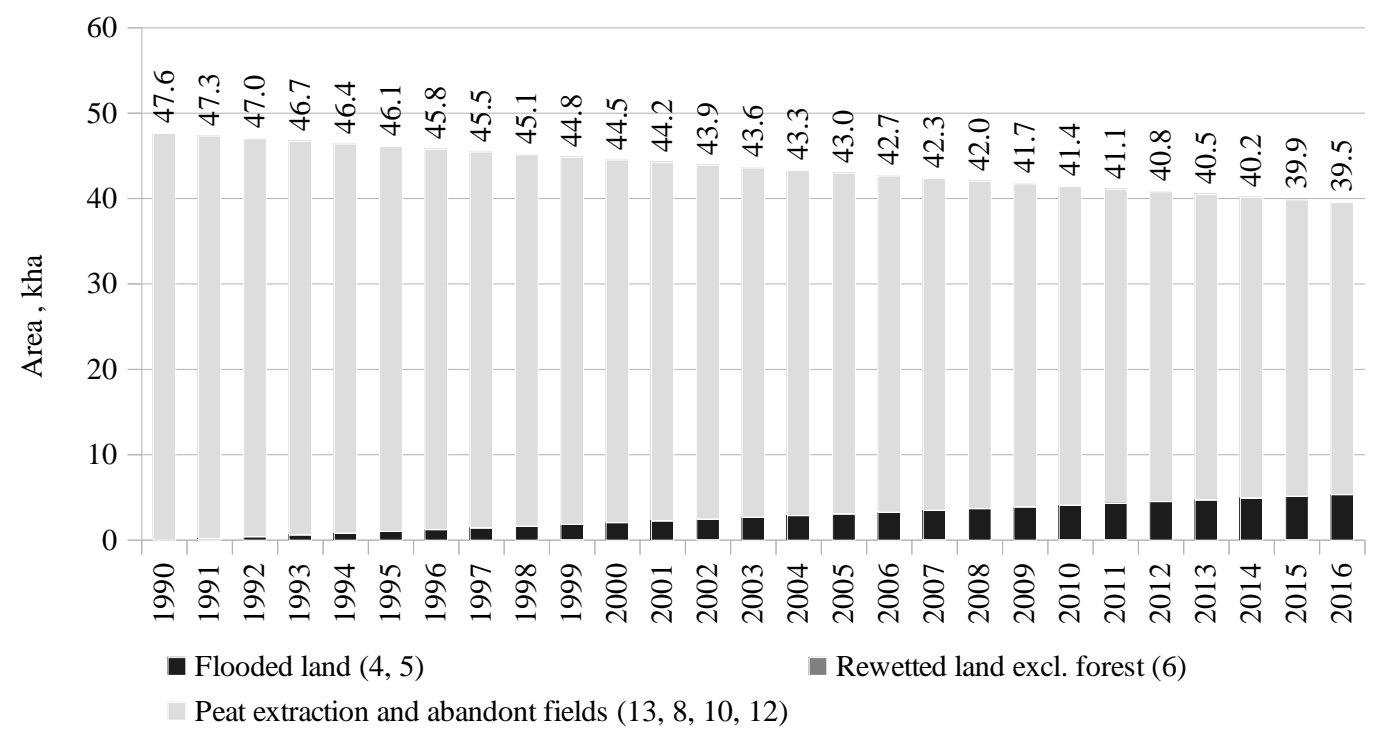

Figure 4. Area which should be reported under wetlands category of the GHG inventory.

areas continuously decreasing, however, the study also approves a necessity to include calculation of emissions from flooded lands in the GHG inventory. Considering that flooded lands are not represented in the GHG inventory report, methodology for calculation of the emissions should be elaborated or a relevant methodology from IPCC 2006 or Wetlands supplements should be applied. The share of rewetted areas is insignificant; therefore, this land use category can be merged with flooded lands and emissions can be calculated using the methodology for flooded lands.

The total area of wetlands drained for peat extraction has been considerably reduced since 1990 (Figure 4); however, it is still bigger than the currently reported area in the GHG inventory report (27.0 kha) due to a large area of temporarily abandoned peat extraction fields $(64 \%$ of the total area in Figure 4 in 2016). These figures should be used in the National GHG inventory to avoid underestimation of GHG emissions due to management of wetlands. The study does not respond to the question if the emission factors for nutrient-rich or poor soils should be applied to these areas, respectively, what is a share of raised bogs (nutrient-poor sites). A conservative approach requires the use of the emission factors for nutrient-rich soils; however, it would lead to a considerable overestimation of the emissions, because most of active licenses were digitized during the study application to nutrient-poor peatlands (raised bogs). The default IPCC 2006 emission factors for nutrientrich and -poor peat extraction fields are equal for the temperate moist climate region; therefore, separation of soils by a fertility class will not result in different GHG emission estimates and total values presented in Figure 4 can be used in GHG calculation until soil type specific emission factors are elaborated.
The default data source for reporting of land use is National forest inventory (NFI). In future, GHG inventory submissions the NFI should be integrated with the more detailed polygon analysis provided in this study to avoid double accounting of the emissions. The area of land summarized in Figure 4 should be reported as wetlands remaining wetlands, the land used for peat extraction. Other land uses and land use changes will be reported within the NFI procedure for reporting of land use changes. Quality assurance should include comparison of the specific land use changes and linearized approach provided in this study and harmonized where necessary.

\section{Conclusions}

1. The study results can be used as land use activity data for calculation of GHG emissions in wetlands category of the National GHG inventory, including land use changes since 1990. However, further improvements are necessary to interpolate land use change data.

2. A linearized approach in calculation of emissions may result in overestimation or underestimation of GHG emissions in certain periods of time; however, the application of the obtained figures avoids underestimation of GHG emissions due to the management of wetlands, as it happens in case of application of the default values available in the inventory guidelines.

3. The area of peat extraction sites is considerably bigger than currently reported in the National GHG inventory, mainly due to the abundance of abandoned peat extraction fields, which are not yet afforested or flooded.

4. There is a need to introduce a new land use category - flooded land - into National GHG 
inventory and to elaborate the methodology for calculation of the emissions.

5. It is necessary to elaborate emission factors for fertile and non-fertile peat extraction sites and continue work on separation of different soils.

\section{Acknowledgments}

The study is implemented within the scope of the EU LIFE program project LIFE14 CCM/LV/001103 'Sustainable and responsible management and re-use of degraded peatlands in Latvia' (LIFE REstore).

\section{References}

1. Baders, E., Senhofa, S., Purina, L., \& Jansons, A. (2017). Natural Succession of Norway Spruce Stands in Hemiboreal Forests: Case Study in Slitere National Park, Latvia. Baltic Forestry, 23(2), 522-528.

2. Bastiaanssen, W.G.M. (1995). Regionalization of surface flux densities and moisture indicators in composite terrain; a remote sensing approach under clear skies in mediterranean climates (PhD thesis). Wageningen Agricultural Univ., The Netherlands. Retrieved February 6, 2018, from: http://edepot.wur. $\mathrm{nl} / 206553$.

3. Blain, D., Boer, R., Eggleston, S., Gonzalez, S., Hiraishi, T., Irving, W., ... Towprayoon, S. (2013). Supplement to the 2006 Guidelines for National Greenhouse Gas Inventories: Wetlands (Wetlands Supplement) (p. 339).

4. Eggleston, S., Buendia, L., Miwa, K., Ngara, T., \& Kiyoto, T. (Eds.). (2006). IPCC Guidelines for National Greenhouse Gas Inventories. Agriculture, Forestry and Other Land Use. In 2006 IPCC Guidelines for National Greenhouse Gas Inventories (Vol. 4, p. 678). Japan: Institute for Global Environmental Strategies (IGES).

5. Gancone, A., Skrebele, A., Līga, R., Ratniece, V., Cakars, I., Sinics, L., ... Priekulis, J. (2017). Latvia's National Inventory Report Submission under UNFCCC and the Kyoto protocol Common Reporting Formats (CRF) 1990-2015 (p. 845). Riga: Ministry of Environmental Protection and Regional Development of the Republic of Latvia.

6. Hiraishi, T., Krug, T., Tanabe, K., Srivastava, N., Fukuda, M., Troxler, T., \& Jamsranjav, B. (2013). Supplement to the 2006 IPCC Guidelines for National Greenhouse Gas Inventories: Wetlands (p. 354). Switzerland: IPCC. Retrieved February 13, 2018, from: http://www.ipcc-nggip.iges.or.jp/public/wetlands/ pdf/Wetlands_Supplement_Entire_Report.pdf.

7. Jansons, Ā., Matisons, R., Šēnhofa, S., Katrevičs, J., \& Jansons, J. (2016). High-frequency variation of treering width of some native and alien tree species in Latvia during the period 1965-2009. Dendrochronologia, 40, 151-158. DOI: 10.1016/j.dendro.2016.10.003.

8. Laiho, R. (2006). Decomposition in peatlands: Reconciling seemingly contrasting results on the impacts of lowered water levels. Soil Biology and Biochemistry, 38(8), 2011-2024. DOI: 16/j.soilbio.2006.02.017.

9. Lupikis, A., Bardule, A., Lazdins, A., Stola, J., \& Butlers, A. (2017). Carbon stock changes in drained arable organic soils in Latvia: results of a pilot study. Agroonomy Research, 15(3), 788-798.

10. Lupikis, A., \& Lazdins, A. (2017). Soil carbon stock changes in transitional mire drained for forestry in Latvia: a case study. In Research for Rural Development (Vol. 1, pp. 55-61). Latvia University of Agriculture.

11. Ministry of Environment and Regional Development of Republic of Latvia. (2015). Latvia's report to facilitate the calculation of the assigned amount for the second commitment period under the Kyoto Protocol (p. 15). Riga. Retrieved February 10, 2018, from: http://unfccc.int/files/national_reports/annex_i_ ghg_inventories/national_inventories_submissions/application/zip/lva-2016-ir-15jun16.zip.

12. Norberg, L. (2017). Greenhouse Gas Emissions from Cultivated Organic Soils (Doctoral thesis). Swedish University of Agricultural Sciences, Uppsala. Retrieved February 10, 2018, from: https://pub.epsilon.slu. se/14284/1/norberg_1_170427.pdf.

13. Penman, J. (Ed.). (2003). Good Practice Guidance for Land Use, Land-Use Change and Forestry. 2108 -11, Kamiyamaguchi, Hayama, Kanagawa, Japan: Institute for Global Environmental Strategies (IGES). Retrieved February 11, 2018, from: http://www.ipcc-nggip.iges.or.jp.

14. Salm, J.-O., Kimmel, K., Uri, V., \& Mander, Ü. (2009). Global Warming Potential of Drained and Undrained Peatlands in Estonia: A Synthesis. Wetlands, 29(4), 1081-1092. DOI: 10.1672/08-206.1.

15. von Arnold, K., Hånell, B., Stendahl, J., \& Klemedtsson, L. (2005). Greenhouse gas fluxes from drained organic forestland in Sweden. Scandinavian Journal of Forest Research, 20(5), 400-411. DOI: $10.1080 / 02827580500281975$. 